\title{
Geometria Riemanniana na educação básica: interdisciplinaridade em ação
}

\author{
RienannianGeometry in basiceducation: interdisciplinarity in action
}

Gabriel Luís da Conceição ${ }^{1}$

\section{Resumo}

Este trabalho apresenta um produto educacional, resultante da pesquisa de Mestrado Profissional em Educação Matemática da Universidade Severino Sombra, onde é discutida a possibilidade de inserção das ideias elementares da Geometria Riemanniana, articulando Matemática e Geografia de forma interdisciplinar, para alunos da educação básica. Em específico, a pesquisa e consequentemente o produtointentam responder as seguintes questões: se a Geometria Riemanniana está presente em nosso dia a dia, por que não abordamos as suas ideias elementares, identificando algumas aplicações nas escolas da educação básica? Mais especificamente: como podemos explorar esses conceitos em sala de aula de maneira interdisciplinar? O estudo é construído pelo aporte metodológico da pesquisa-ação. Identifica-se com a pesquisa a possibilidade de aplicação das ideias elementares da Geometria Riemanniana a alunos da escola básica, bem como é apresentada uma proposta para esta efetivação.

Palavras-chave: Educação Matemática; Geometria Riemanniana; Interdisciplinaridade.

\section{Abstract}

This work presents an educational product, resulting from the research of the Professional Masters in Mathematical Education of SeverinoSombra University, where the possibility of insertion of the elementary ideas of Riemannian Geometry, articulating Mathematics and Geography in an interdisciplinary way, for students of basic education is discussed. Specifically, the research and consequently the product tries to answer the following questions: if Riemannian Geometry is present in our daily life, why not address its elementary ideas, identifying some applications in primary schools? More specifically: how can we explore these concepts in the classroom in an interdisciplinary way? The study is constructed by the methodological contribution of action research. It identifies with the research the possibility of applying the elementary ideas of the Riemannian Geometry to students of the basic school, as well as a proposal for this realization is presented.

Keywords:Mathematical Education; Riemannian geometry; Interdisciplinarity

1'Doutorando em Ciências pela Universidade Federal de São Paulo - UNIFESP. Mestre em Educação Matemática pela Universidade Severino Sombra - USS. Professor do Centro Universitário Geraldo $\mathrm{Di}$ Biase - UGB e da Faculdade Sul Fluminense (FaSF). gabrielluis_matematica@yahoo.com.br 


\section{INTRODUÇÃO}

As Geometrias são fundamentais na Matemática, no entanto, muitas vezes são apresentadas de forma axiomática e dissociada de outras áreas do conhecimento, o que é impróprio, pois vivemos rodeados das formas geométricas. Segundo Fainguelernt,

A importância da geometria é inquestionável, tanto sob o ponto de vista de suas aplicações práticas quanto do aspecto do desenvolvimento de diferentes competências e habilidades necessárias à formação de qualquer indivíduo. Ela é uma poderosa ferramenta para a compreensão, descrição e interrelação com o espaço em que vivemos. (2012, p. 113).

A Geometria Riemanniana, uma das geometrias não euclidianas, possui inúmeras aplicabilidades e se relaciona diretamente com conteúdos estudados em Geografia, no entanto, após levantamento das propostas curriculares em diferentes estados do Brasil, somente verifica-se referência ao estudo dos conceitos iniciais das Geometrias não euclidianas no estado do Paraná.

A Geometria ensinada na educação básica, e que está nos livros didáticos são a Geometria Plana e a Espacial, fundamentadas por Euclides em sua mais importante obra, OsElementos. No entanto, mesmo estudando somente a Geometria de Euclides, esses mesmos alunos, ao estudarem o globo terrestre em Geografia, utilizam algumas ideias da Geometria de Riemann, mesmo sem saberem se tratar de uma geometria diferente da que eles aprendem. É um exemplo de como o ensino é fragmentado, identificando a não conexão da Matemática com as outras áreas do conhecimento.

$\mathrm{Na}$ maioria dos casos, os professores, tanto de Matemática como de Geografia, desconhecem essa geometria e as relações entre as duas, fato evidenciado ao questionarmos professores destas áreas do conhecimento. Com exceção de dois professores de Matemática, nenhum outro sequer ouviu falar sobre alguma Geometria não euclidiana. Isto também foi confirmado por uma pesquisa realizada na Universidade Federal Fluminense (UFF):

Estudos realizados na UFF com 53 professores de matemática do ensino fundamental e médio, apontam que desses, $7 \%$ não sabem o que seja plano euclidiano, quase $18 \%$ desconhecem quais são os seus axiomas e $20 \%$ não sabem o que seja o $5^{\circ}$ axioma de Euclides. Além disso, quase $34 \%$ não 
sabem o que são geometrias não-euclidianas e quase $54 \%$ não estudaram estas geometrias em seus cursos de formação. (KALLEF, 2004, p.3)

A partir disso, percebe-se a necessidade de apresentar aos nossos alunos uma Geometria importante a ser conhecida, pois não vivemos em um planeta plano, e é necessário criar significados em relação aos elementos aprendidos na Geografia, a fim de que ele compreenda as relações entre as disciplinas e interprete os elementos do globo terrestre.

Gostaríamos de tornar claro que não se propõe trabalhar os complexos cálculos geométricos de Riemann na educação básica, mas sim apresentar as ideias elementares desta geometria tão presente no nosso cotidiano. Como exemplo de aplicação podemos citar a aviação, a navegação e os modernos aparelhos de GPS², frequentemente utilizados nos dias atuais.

Os objetivos deste trabalho são, discutir de forma interdisciplinar, e apresentar possibilidades de ensinodas ideias iniciais da Geometria de Riemann na educação básica, relacionando-a com a Geografia, disciplina que envolve o estudo do globo terrestre. Objetiva-se ainda, propor exercícios, problemas e atividades para que professores utilizem e apliquem na educação básica. Utilizase como metodologia, a pesquisa-ação.

Vários questionamentos matemáticos podem surgir nas aulas de Geografia, e como nossos alunos obterão respostas a essas perguntas, se não apresentarmos as noções intuitivas e elementares dessa Geometria? Estamos ainda fundamentados nos Parâmetros Curriculares Nacionais do Ensino Médio (PCNEM) que nos mostram que deve haver "aprendizagem contextualizada, integrada e relacionada a outros conhecimentos" (BRASIL, 1999, p. 111).

Além disso, os Parâmetros Curriculares Nacionais para o Ensino Fundamental (PCNEF) nos dizem para incluirmos em nossas aulas uma pluralidade de modelos geométricos.

${ }^{2}$ Sistema de Posicionamento Global 
Fruto da criação e invenção humana, a Matemática não se desenvolveu de forma linear e logicamente organizada. Desenvolveu-se com movimentos de idas e vindas, com ruptura de paradigmas. [...] Uma instância importante de mudança de paradigma ocorreu quando se superou a visão de uma única geometria do real, a geometria euclidiana, para a aceitação de uma pluralidade de modelos geométricos. (BRASIL, 1998, p. 25)

Percebe-se ainda que as orientações acima transcritas do PCNEF são aplicadas nas Diretrizes Curriculares do Estado do Paraná (2008), que afirmam que a Geometria Euclidiana não consegue resolver todos os problemas do mundo real, precisando de fundamentos das Geometrias não euclidianas.

Por essas razões, justificamos o estudo e a construção do produto relativo das geometrias não euclidianas, mais especificamente da Geometria de Riemann, e lamentamos a não utilização desses conceitos iniciais na educação básica, pois "ela é tão bonita e singela que dá pena ver como foi relegada ao esquecimento" (LIMA, 2001).

Dessa forma, a pesquisa está baseada nos seguintes questionamentos: Se a Geometria de Riemann, assim como as outras várias geometrias não euclidianas fazem parte do nosso cotidiano, porque não se abordam os seus conceitos elementares, identificando algumas aplicações nas escolas da educação básica? Como ensiná-las?

Neste trabalho, produto do Programa de Mestrado Profissional em Educação Matemática da Universidade Severino Sombra, são apresentadas atividades relativas à Geometria de Riemann. Além disso, pretende-se que com este material, se produzam discussões sobre a validade da utilização dessa geometria nas salas de aula do ensino médio, até mesmo, com adaptações, nas do ensino fundamental.

\section{UM POUCO DE HISTÓRIA}

Não podemos iniciar uma história que envolva Geometria sem antes falarmos de Euclides (cerca de 325 a.C a 265 a.C), sobre ele temos poucas informações, "e esse pouco que sabemos nos vem dos comentários de Proclus 
(410-485), um autor que viveu mais de 700 anos depois de Euclides" (ÁVILA 2001, p.1).

Segundo Brito (1995, p.34), não se sabe ao certo onde ele nasceu, e nem qual era a sua formação. Acredita-se que tenha estudado na academia de Platão, em Atenas, pelas semelhanças entre a visão platônica do conhecimento e que por isso teve acesso aos trabalhos dos geômetras da época. Sabe-se ainda que ensinou em Alexandria (Egito), no reinado de Ptolomeu I (306 a.C - 283 a.C), onde o rei criou o chamado Museu, que se tratava de um "instituto científico" da época, sob a responsabilidade do governo, onde Euclides ensinava.

Euclides foi o primeiro a apresentar a matemática, em especial a Geometria, de forma sistemática e organizada, dando origem ao que hoje chamamos de Os Elementos ${ }^{3}$, sua mais importante obra.

Segundo Ávila (2001) não se sabe ao certo se Euclides escreveu a obra para ensinar, ou para reunir todo o conhecimento matemático da época. Os Elementos, contém todo o conhecimento matemático grego desenvolvido desde Tales (século VI a.C) até Euclides. Segundo Katz (1998, p. 59), depois da Bíblia, a obra Os Elementos é o livro mais estudado e reproduzido no mundo ocidental.

Os volumes que constituem Os Elementosforam publicados por volta de 300 a.C, e constituem-se de 13 livros ou capítulos contendo120 definições, 372 teoremas, 93 problemas, 19 corolários, 13 lemas, 5postulados e 5 axiomas, e ele possui uma linguagem, que para a época, era extremamente rigorosa.

O livro 1 conta com 5 postulados e 9 axiomas (ou noções comuns) que aparecem após serem apresentadas 23 definições. Segundo Euclides, as nove noções comuns são:

1 - As coisas iguais à mesma coisa são também iguais entre si.

$2-\mathrm{E}$, caso sejam adicionadas coisas iguais a coisas iguais, os todos são iguais.

$3-\mathrm{E}$, caso de iguais sejam subtraídas iguais, as restantes são iguais.

$4-E$, caso iguais sejam adicionadas a desiguais, os todos são desiguais.

5 - E os dobros da mesma coisa são iguais entre si.

$6-\mathrm{E}$ as metades da mesma coisa são iguais entre si.

$7-E$, as coisas que se ajustam uma à outra são iguais entre si.

8 - E o todo [é] maior do que a parte.

9 - E duas retas não contêm uma área.(EUCLIDES, 2009 p. 98)

${ }^{3}$ Do grego, "Stoicheia". 


\section{E os postulados:}

$1^{\circ}$ postulado: Fique postulado traçar uma reta a partir de todo ponto até todo ponto. $2^{\circ}$ postulado: Também prolongar uma reta limitada, continuamente, sobre uma reta. $3^{\circ}$ postulado: E, com todo centro e distância, descrever um

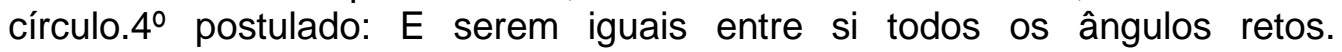
(EUCLIDES, 2009, p.98)

Os quatro postulados enunciados anteriormente nunca foram questionados e, por cerca de dois mil anos, a geometria apresentada por Euclides era considerada como única. A obra Os Elementos era inquestionável, no entanto, ao se tentar demonstrar o quinto postulado a partir dos quatro anteriores, gerou uma série de questionamentos.

Euclides redigiu o quinto postulado na obra os Elementos da seguinte forma: "E, caso uma reta, caindo sobre duas retas, faça ângulos interiores e do mesmo lado menores do que dois retos, sendo prolongadas as duas retas, ilimitadamente, encontrarem-se no lado no qual estão os menores do que dois retos" (EUCLIDES, 2009, p. 98). Hoje o conhecemos como "por um ponto do plano fora de uma reta passa uma única reta paralela a essa reta (retas paralelas de um plano são aquelas que prolongadas indefinidamente não se encontram)" (DANTE, 2008, p. 79).

Segundo Garbi (2006), ao longo dos tempos, muitos matemáticos buscaram provar o quinto postulado a partir dos quatro anteriores. Já mesmo na época em que o escreveu, o próprio Euclides apresentava dificuldades para verificar se tratava de um postulado ou de um teorema, pois, segundo Barbosa (2009, p. 7), existem "evidências históricas de que o quinto postulado se tornou o principal alvo de críticas aos Elementos ainda no tempo de Euclides". Estes estudos geraram discussões de mais de dois mil anos, pois a obra de Euclides apresentava uma bela estruturação lógica e questioná-la poderia parecer absurdo. Este postulado rendeu a famosa frase do matemático francês D’Alembert: "A definição de reta e de paralelas, na obra de Euclides, constituem o escândalo da geometria" (COUTINHO, 2001, p. 36).

Os principais matemáticos que tentaram buscar a demonstração do $5^{\circ}$ postulado foram: Ptolomeu (367 a.C - 283 a.C), Proclus (410-485), Nasir (1201- 
1274), John Wallis (1616-1703), Saccheri (1667-1733) e Lambert (1728-1777). Estes matemáticos esbarraram em alguns impasses, pois suas demonstrações equivaliam ao quinto postulado.

Em meados do século XVIII ao final do século XIX, outros matemáticos realizaram estudos e apresentaram soluções satisfatórias para os impasses. Foram eles: Gauss (1777-1855), Lobachevsky (1872-1856), Bolyai (1802-1860) e Riemann (1826-1866).

Riemann fundamentou uma Geometria com base na superfície esférica, que passou a ser conhecida como Geometria Riemanniana.

[...] Como Riemann mudou a nossa forma de pensar, é difícil indicar onde exatamente ele influenciou o trabalho dos outros [...]. A matemática reconhecidamente moderna começou com Riemann. As conseqüências do que ele disse na sua apresentação só seriam digeridas e apreciadas muitos anos depois (GAUSS apud O'SHEA, 2009, p. 132).

Vale ressaltar que essa descoberta não se deve unicamente a Riemann ou aos matemáticos do século XIX. Ela é a união do trabalho árduo de vários matemáticos citados anteriormente que tentaram provar o quinto postulado sem sucesso, e abriram caminho para os matemáticos que lhes sucederam.

As geometrias não-euclidianas não vieram para substituir a euclidiana, e sim para somar ao conhecimento geométrico já existente e disseminado por Euclides em sua obra. Não são geometrias que negam a euclidiana, que é de extrema utilidade na matemática, no entanto existem diferenças entre elas no tratamento quanto às retas paralelas e alguns outros tópicos geométricos.

Segundo Coutinho (2001), a partir da substituição do postulado das paralelas, surgiram duas clássicas geometrias não-euclidianas: a de Lobackevisky (hiperbólica) e a de Riemann (elíptica ou esférica), que não são as únicas geometrias não euclidianas. Existem ainda várias outras, tais como a Geometria Projetiva, a Geometria Fractal, a Geometria Topológica, etc, porém neste trabalho nos deteremos na Geometria de Riemann, onde apresentaremos um produto com atividades a serem aplicadas a alunos da educação básica envolvendo ideias iniciais desta Geometria e da Geografia, de forma interdisciplinar. 


\section{A GEOMETRIA RIEMANNIANA E ALGUMAS DE SUAS IDEIAS ELEMENTARES}

Na Geometria de Riemann deixamos para trás a noção de "estar entre" e o conceito de reta diferencia-se do conceito da geometria euclidiana. Nesta geometria, a reta não é mais infinita, e sim ilimitada.

O axioma que nega o quinto postulado de Euclides para o plano de Riemann diz que: "Quaisquer duas retas em um plano tem um ponto de encontro". (COUTINHO, 2001, p. 73). Para interpretarmos o axioma apresentado, é só pensarmos na superfície esférica. Nessa superfície todas as retas, ou seja, circunferências máximas, se intersectam em mais de um ponto. Assim na Geometria de Riemann não existem retas paralelas e nem retas secantes: todas se encontram.

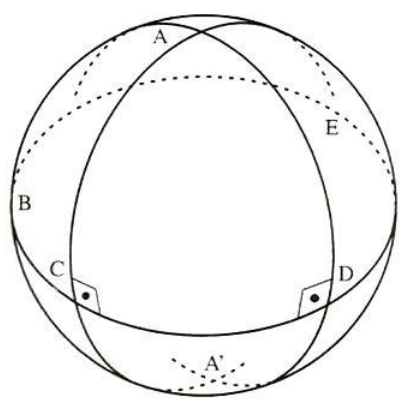

Figura 1: Retas representadas no plano de Riemann Fonte: Coutinho (2001)

Com o surgimento das geometrias não euclidianas, findaram-se as discussões a cerca do quinto postulado de Euclides, sendo agora um postulado diferente dos demais e exclusivo da geometria euclidiana. Com isso cai-se por terra também a discussão de qual geometria é verdadeira e qual não é.

A seguir apresentaremos ideias elementares da Geometria Riemanniana, que estão associadas as atividades propostas.

Esfera: Sendo C um ponto, e r uma dada medida, com $r>0$. Chamamos de esfera com centro $\mathrm{C}$ e raio r o conjunto dos pontos do espaço, cuja distância até o ponto $\mathrm{C}$ é menor ou igual a $r$. 


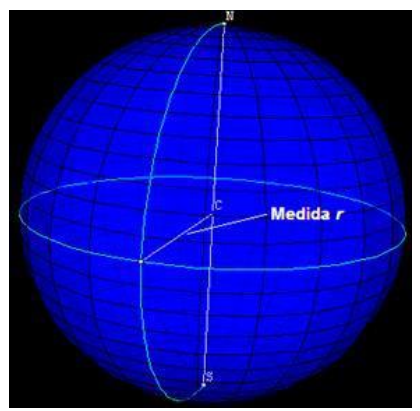

Figura 2: Esfera construída no applet Java Earth ${ }^{4}$

Superfície esférica: Antes de falarmos de superfície esférica precisamos definir superfície. Segundo Fonte (2006/2007, p. 3), superfície de um corpo é o "conjunto de pontos que separam os pontos do espaço que pertencem ao corpo dos pontos do espaço que não lhe pertencem. As superfícies são geradas pelo movimento de linhas deformáveis ou indeformáveis". Superfície é a "parte exterior e visível aos olhos". Apresentamos exemplos de três superfícies diferentes:

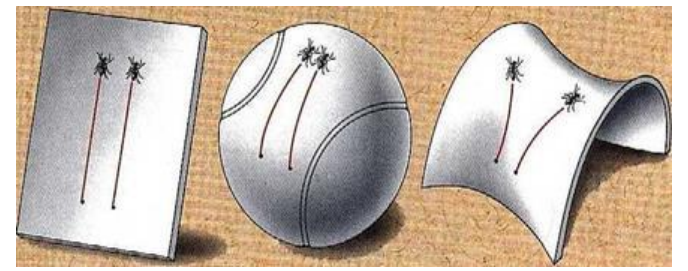

Figura 3: Superfícies plana, esférica e hiperbólica Fonte: Fonte (2006/2007)

Agora que já definimos superfície, podemos falar da superfície esférica. Segundo Souza (1997, p.3) "uma superfície esférica é uma superfície de 2o ordem $^{5}$, de revolução, limitada e fechada, gerada por uma circunferência que roda em torno de um dos diâmetros".

Elementos da Superfície Esférica:Os principais elementos contidos na superfície esférica são: eixo, polos, equador, paralelo e meridiano, abaixo falaremos um pouco de cada um deles:

\footnotetext{
${ }^{4}$ Disponível em: http://www.professores.uff.br/hjbortol/arquivo/2006.1/applets/earth_br.html 5 O número de ordem de uma superfície é dado pelo número máximo de pontos que uma reta encontra essa superfície.
} 


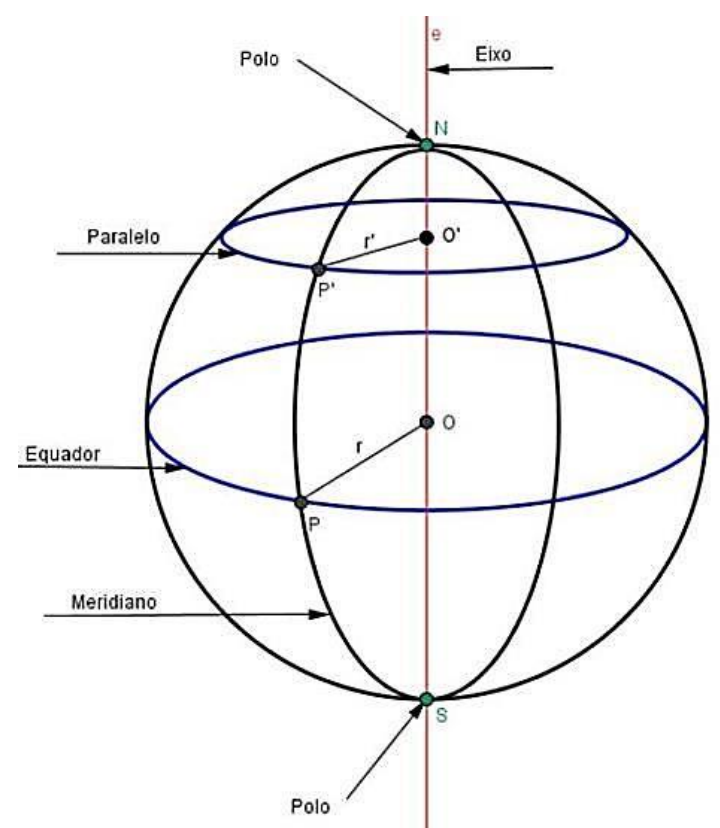

Figura 4: Elementos da Superfície Esférica Fonte: Zanella (2011)

I) Eixo: Trata-se de qualquer reta que contém centro.

II) Polos: São os pontos de interseção entre a superfície esférica e o eixo.

III) Equador: Circunferência máxima tal que o plano que a contém forma ângulo de $90^{\circ} \mathrm{com}$ o eixo.

IV) Paralelo: Circunferência tal que o plano que a contém forma ângulo de $90^{\circ}$ com o eixo. Nos livros de Geografia há ainda a informação de que essa circunferência é paralela ${ }^{6}$ ao Equador.

v) Meridiano:Circunferência máxima que contém os polos.

Circunferência Máxima7: São circunferências de maior raio contidas na superfície esférica. "Consideremos uma esfera e um plano contendo o seu centro. A intersecção do plano com a superfície esférica é uma circunferência máxima. São estas circunferências [..] que substituem as rectas da geometria plana."

\footnotetext{
${ }^{6} \mathrm{Na}$ Geometria Riemanniana não existem retas paralelas.

7 Algumas referências também denominam como círculo máximo, no entanto fixaremos neste trabalho circunferência máxima, pois sabemos que circunferência e círculo não são sinônimos.
} 
VELOSO (1928, p. 331). Assim, as retas da superfície Euclidiana são substituídas pelas circunferências máximas na superfície Riemanniana.

Vale ressaltar que segundo o mesmo autor (1928, p. 331 e 332), na Geometria Euclidiana, dados dois pontos, existe uma única reta que passa por esses dois pontos. Na Geometria Riemanniana, dados dois pontos, eles podem ser antípodas ${ }^{8}$, ou seja, existem infinitas circunferências máximas que contém dois pontos.

Dessa forma, se dois pontos definem mais de uma circunferência máxima, e duas circunferências máximas sempre se encontram em dois pontos, "se definirmos que duas circunferências máximas são paralelas quando não tem ponto em comum, vemos que não existem circunferências máximas paralelas" VELOSO (1928, p. 332)

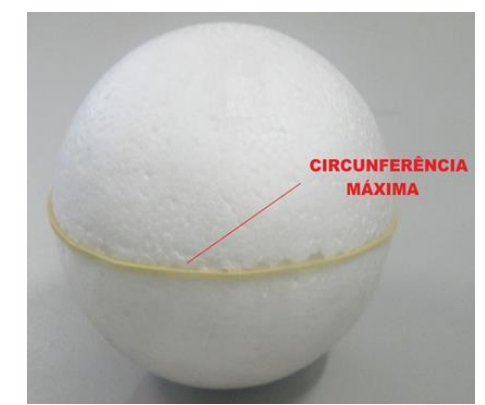

Figura 5: Circunferência máxima representada com um elástico . Fonte: $\mathrm{O}$ autor.

Triângulo Esférico:Trata-se de um triângulo construído sobre a superfície esférica. "Quando queremos definir um triângulo esférico, temos que partir de três circunferências máximas, isto é, os lados de um triângulo esférico são sempre arcos de circunferência máxima”. VELOSO (1928, p. 333). E diferentemente da geometria euclidiana a soma de seus ângulos internos não é uma constante, é maior que $180^{\circ}$ e menor que $540^{\circ}$. Eles ainda podem ser trirretângulos (três ângulos retos), birretângulo (dois ângulos retos) ou retângulos (um ângulo reto).

\footnotetext{
8 Pontos opostos diametralmente um do outro.

${ }^{9}$ As ideias elementares de Riemman concretizados em esferas de isopor neste trabalho são resultado de oficinas ministradas pelo autor com alunos da escola básica.
} 
Figura 6: Triângulo esférico construído com alfinetes e elástico.

Fonte: $\mathrm{O}$ autor.

Geodésica: "De uma maneira geral chama-se geodésica à linha que, sobre uma superfície, representa o trajeto mais curto entre dois pontos dados" VELOSO (1928, p. 331)

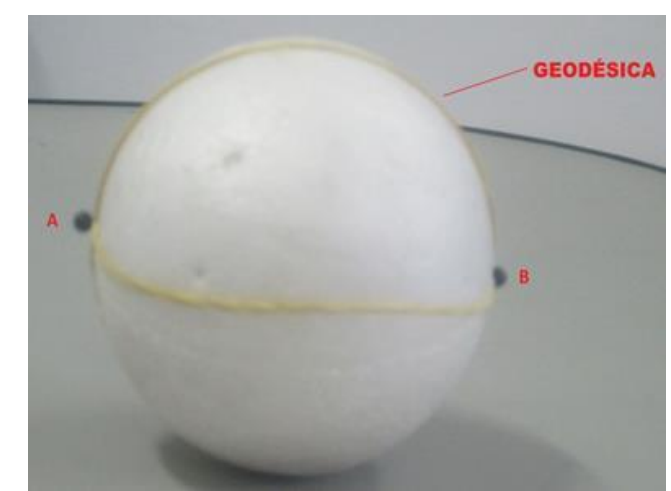

Figura 7: Geodésica construída com elástico e alfinetes.

Fonte: $\mathrm{O}$ autor.

Distância entre dois pontos em uma superfície esférica: "A distância entre dois pontos é o comprimento do arco de circunferência máxima compreendido entre os dois" VELOSO (1928, p. 332) 


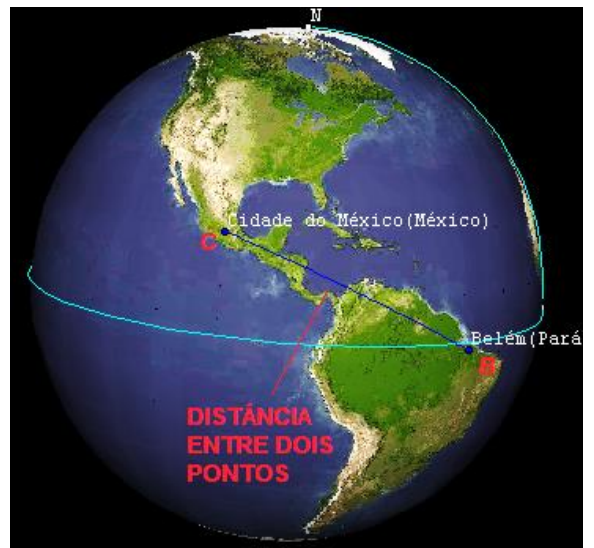

Figura 8: Distância entre dois pontos (BC) no Globo Terrestre determinada Fonte: applet Earth

\section{O PRODUTO EDUCACIONAL}

O produto educacional gerado coma pesquisa, trata-se de uma coletânea com um conjunto de atividades para professores da escola básica. Sugerimos que sejam utilizados os seguintes materiais: Globo Terrestre; Esferas de Isopor com raios de tamanhos variados; elásticos; alfinetes; réguas flexíveis e transferidores;

Entende-se que a utilização dos materiais manipuláveis e a visualização são de suma importância para a compreensão de conceitos geométricos a serem construídos, pois "uma imagem visual não apenas organiza os dados disponíveis em estruturas significativas, mas também é um fator importante na orientação do desenvolvimento analítico de uma solução" (FAINGUERLERT e NUNES, 1999, p.55)

Além disso, sugerimos que o ambiente contenha computadores conectados à Internet e projetor multimídia, para que se possa fazer uso do ambiente de geometria dinâmica, disponibilizado no rede mundial de computadores $^{10}$, de autoria do professor Humberto José Bortolossi, da Universidade Federal Fluminense (UFF). Este ambiente é um aplicativo Java, que faz parte do projeto "Visualização Científica: Deformações em Mapas Cartográficos", construído em parceria com Jonas Hurrelmann e Konrad Polthier da Freie Universitat na Alemanha. Segundo Bortolossi:

\footnotetext{
10 Disponível em: http://www.professores.uff.br/hjbortol/arquivo/2006.1/applets/earth_br.html
} 
O aplicativo permite esclarecer o conceito de latitude e longitude, bem como visualizar os vários elementos geográficos do globo terrestre: meridianos, paralelos, pólos, divisões políticas e a localização de capitais de boa parte dos países. Mais ainda para cada país existe um link correspondente para a enciclopédia Wikipédia, permitindo assim que o usuário tenha rápido acesso a dados históricos, políticos, econômicos, geográficos e demográficos, etc. Quase todos os países foram incluídos no applet. Excluímos aqueles cuja área territorial é muito pequena

A tecnologia do applet como material complementar às atividades contribui de forma efetiva para o aprendizado, além de serem motivadoras no processo, pois:

Manipulando diretamente os objetos na tela do computador, e com realimentação imediata, os alunos questionam 0 resultado de suas ações/operações, conjecturam e testam a validade das conjecturas inicialmente através dos recursos de natureza empírica". (GRAVINA, 1996 p. 89-90)

É também notória a importância em se trabalhar diferentes representações, aliando os materiais concretos com as ferramentas computacionais, de forma que o aluno possa realizar as atividades de diferentes formas identificando as características e propriedades. Segundo SchoemFeld, apud Fainguelernt, (1999, p.58), "[...] a habilidade de pensar em termos de diferentes tipos de sistemas de representação favorece o bom desempenho e a competência no pensar matemático, em particular no pensar geométrico". No entanto, que fique claro que a utilização dos materiais concretos bem como da tecnologia, por si só não produzem a compreensão e construção dos conceitos geométricos.

Recursos didáticos como jogos, livros, vídeos, calculadoras, computadores e outros materiais têm um papel importante no processo de ensino e aprendizagem. Contudo, eles precisam estar integrados a situações que levem ao exercício da análise e da reflexão, em última instância, a base da atividade matemática. (PCN, 1997, p.19)

Para que ocorra a compreensão e a construção dos conceitos geométricos é necessário desenvolvermos atividades investigativas, afim de que o aluno assuma uma posição ativa no processo, e também se sinta no papel de investigador, logo construtor do seu conhecimento. Essa ideia é corroborada por Fainguelernt: 
Na geometria há um imenso campo para a escolha de tarefas de natureza exploratória e investigativa que podem ser desenvolvidas em sala de aula sem a necessidade de um grande número de pré-requisitos. Com esse tipo de atividade os alunos passam a assumir um papel mais ativo e autônomo nas aulas. Eles exploram situações e ideias, fazem e testam conjecturas, generalizam, justificam e provam alguns resultados (2012, p 128)

Como afirma essa autora, a geometria é um campo propício a este processo exploratório.

As atividades aqui propostas foram baseadas no trabalho desenvolvido pela professora Mara Lucia Thomaz, intitulado Produção Didático Pedagógica: Professor PDE $2007^{11}$, vinculado à Universidade Estadual de Maringá.

As atividades possuem os seguintes objetivos:

1) Apresentar a evolução dos conceitos geométricos, iniciando pela Geometria Euclidiana, mostrando a história acerca da negação do quinto postulado enunciado por Euclides até a chegada das Geometrias NãoEuclidianas, especificamente a Geometria de Riemann;

2) Buscar a integração entre os conceitos matemáticos e geográficos, através da representação e dos conceitos da Geometria de Riemann aplicados no globo terrestre

3) $E$, que os alunos compreendam os principais conceitos relativos à Geometria de Riemann de forma a compará-los e confrontá-los com a Geometria de Euclides.

As atividades estão subdivididas da seguinte forma:

1aㅡ atividade: Comparação entre a geometriaRiemanniana e a Euclidiana.

2 ${ }^{a}$ atividade: Introdução ao conceito de geodésica, para que o aluno possa diferenciar a reta na Geometria Euclidiana e a reta na GeometriaRiemanniana.

3a atividade: Verificação de que na geometria plana a distância entre dois pontos é uma reta, e na de Riemann, um arco.

4ª atividade: Constatação de que na Geometria de Riemann não existem retas paralelas.

5a e 6 atividades: Apresentação do triângulo esférico, suas características e propriedades.

Sugerimos que os alunos envolvidos na realização das atividades sejam divididos em equipes, pois entendemos que a discussão é uma etapa de grande importância nos processos de ensino e de aprendizagem.

\footnotetext{
${ }^{11}$ Adaptadas de Thomaz. Disponível em:

www.gestãoescolar.diaadia.pr.gov.br/arquivos/File/producoes_pde/md_mara_lucia_thomaz.pdf
} 
A fase de discussão é, pois, fundamental para que os alunos, por um lado ganhem um entendimento mais rico do que significa investigar e, por outro, desenvolvam a capacidade de comunicar matematicamente e de refletir sobre o seu trabalho e o seu poder de argumentação. Podemos mesmo afirmar que, sem discussão final, se corre o risco de perder o sentido da investigação. (PONTE et al., 2003, p. 41)

\section{9- Atividade:}

A primeira atividade propostaconsiste em uma atividade motivacional que apresenta relações diretas entre a Geometria de Riemann e a Geografia.

"Um caçador saiu de sua casa e caminhou $10 \mathrm{~km}$ ao sul. Depois virou ao oeste e caminhou mais $10 \mathrm{~km}$. Então virou e caminhou novamente por mais $10 \mathrm{~km}$ ao norte. Ficou espantado, pois descobriu que voltou novamente à sua casa".

a) Desenhe em uma folha de papel o caminho percorrido pelo caçador.

b) De acordo com a situação acima, é possível que o caçador volte ao ponto de partida? Anote as suas conclusões.

c) Desenhe em uma esfera de isopor o caminho percorrido pelo caçador.

d) Analisando o caminho desenhado na bola, é possível para o caçador voltar ao ponto de partida?

e) Anote as suas conclusões.

Aqui, o professor, pode relembrar alguns conceitos relativos às coordenadas geográficas como norte, sul, leste e oeste, e para isso pode fazer uso do appletEarth, onde, manipulando o globo terrestre com a interatividade do software os alunos podem relembrar esses conceitos, e para alguns, fixar a as coordenadas cartesianas.

\section{2a Atividade}

Esta atividade, tem objetivo de diferenciar a reta na superfície euclidiana da reta na superfície esférica e introduzir o conceito de geodésica.

"Agora imagine esse mesmo caçador. Ele resolveu sair de casa e caminhar em linha reta infinitamente".

a) Desenhe o caminho percorrido pelo caçador em uma folha de papel.

b) De acordo com o caminho percorrido desenhado na folha de papel, é possível para o caçador voltar ao ponto de partida?

c) Desenhe o caminho percorrido pelo caçador em uma esfera de isopor.

d) De acordo com o caminho percorrido desenhado na esfera, é possível para o caçador voltar ao ponto de partida?

e) Anote suas conclusões. 
Espera-se que os alunos percebam que a reta na Geometria Riemannianaé a circunferência máxima construída sobre a esfera. Neste momento, o professor pode formalizar a concepção de reta em ambas as Geometrias. Sugerimos iniciar apresentando a "definição" de reta dada por Euclides, nos Elementos: "E linha reta é a que está posta por igual com os pontos sobre si mesma" (2009, p. 97). A linguagem da época não ajuda muito, no entanto pode ser motivadora para as discussões, de forma que consiga construir conjuntamente com a linguagem atual a ideia de reta: a "linha" que é possível traçar no planoa partir de dois pontos distintos, lembrando que se trata apenas de uma representação de algo que "cresce" infinitamente nos dois sentidos. Quando conseguir a assimilação do "conceito" de geodésica, pode-se fazer uso daGeometria Dinâmica, através do aplicativo earth, onde os alunos podem manipular o globo terrestre, bem como visualizar as retas na superfície esférica através da representação das distâncias entre os diferentes países do mundo.

\section{3a Atividade}

O objetivo desta atividade é mostrar que na Geometria Plana, a distância entre dois pontos é a menor medida do comprimento de um segmento de reta e na Geometria Riemanniana, é a de um arco, o que também representa a menor distância entre esses pontos. Para isso, propomos:

"Agora o caçador vai caminhar, sobre uma linha reta, da sua casa até a floresta".

a) Desenhe numa folha de papel o caminho percorrido pelo caçador

b) Construa com elásticos em uma esfera de isopor o caminho percorrido pelo caçador:

c) Qual a diferença entre as duas atividades?

Formalizada as concepções, pode-se mais uma vez explorar 0 softwareearth, onde os alunos podem na prática perceber que o caminho e a distância entre duas cidades/países estão associados ao menor arco. 


\section{4⿳亠丷厂 atividade}

Esta atividade objetiva explorar o conceito riemanniano de que nesta geometria não existem retas paralelas, pois cada uma das retas representadas é uma circunferência máxima da esfera, e logo nunca serão paralelas.

"Agora o caçador vai caminhar levando o seu fiel amigo cachorro. Eles vão caminhar paralelamente".

a) Desenhe em uma folha de papel o caminho percorrido pelo caçador e pelo cachorro:

b) Desenhe ou construa com elásticos em uma bola de isopor o caminho percorrido pelo caçador e pelo cachorro:

Vale ressaltar com os alunos, como forma de fixação, que os paralelos ${ }^{12}$ não são retas paralelas.

c) É possível traçar retas paralelas para representar o caminho percorrido pelo caçador e pelo cachorro na folha de papel e na esfera de isopor?

d) Anote suas conclusões.

\section{5 atividade}

Estas duas atividades têm como objetivo apresentar o triângulo esférico, suas características e propriedades. Para isso propomos:

a) Desenhe um triângulo qualquer numa folha de papel e com um transferidor meça os seus ângulos e anote os resultados.

b) Desenhe um triângulo qualquer em uma esfera de isopor, meça os seus ângulos e anote os resultados:

c) A que conclusão você chegou?

Neste momento, o professor pode discutir com os alunos sobre 0 comportamento dos ângulos internos de um triângulo esférico.

\section{6a Atividade:}

"Construa com elásticos uma circunferência máxima em uma esfera de isopor. Em seguida, construa outra circunferência máxima perpendicular à primeira e represente uma terceira circunferência máxima, perpendicular as duas já construídas".

Com a quinta e a sexta atividades os alunos poderão perceber como se dá o comportamento das retas na Geometria Riemanniana, bem como poderão explorar os triângulos formados pela interseção dessas retas.

\footnotetext{
${ }^{12}$ Linhas imaginárias representadas no globo terrestre.
} 


\section{CONSIDERAÇÕES FINAIS}

Este trabalho buscou discutir a utilização da Geometria Riemanniana na escola básica, explicando o seu histórico, sua relação com a Geometria Euclidiana, e propondo atividades para serem executadas com os alunos, aqui designado por produto educacional, a fim de que sejam utilizadas paralelamente aos conteúdos propostos no currículo de Matemática, proporcionando a sua inserção gradual.

Esperamos que os objetivos propostos no produtosejam alcançados e, que se possa verificar, que as ideias elementares da Geometria Riemanniana são ideias possíveis de serem trabalhadas na educação básica. Não exploramos os seus complexos cálculos, e nem é o nosso objetivo, mas sim as suas ideias elementares, extremamente aplicáveis no nosso cotidiano, afinal vivemos em um planeta aproximadamente esférico.

As atividades possibilitam a oportunidade de trocar experiênciascom os alunos, e com outros professores de Matemática e Geografia, de forma a tornar o ambiente de aprendizagem mais agradável, estimulante e motivador.

Todos os momentos das atividades são importantes, e tem o seu devido valor, do erro ao acerto, e isto deve ser valorizado, de forma que a utilização das atividades contribuade forma efetiva na aprendizagem, e dê a oportunidade de conhecer uma Geometria que talvez os alunos não terão a oportunidade de aprender nas salas de aula da educação básica.

Espera-se ainda que as atividades gerem reflexões sobre a possibilidade da inclusão desta geometria nos currículos da educação básica, de forma contextualizada e interdisciplinar, tal como esta proposta.

\section{REFERÊNCIAS}

ÁVILA, G. Euclides, Geometria e Fundamentos. Revista do Professor de Matemática. São Paulo, n. 45, p.1, 2001. Disponível em: http://educadores.diaadia.pr.gov.br/arquivos/File/2010/veiculos de comunicacao/RPM/R PM45/RPM45 01.PDF. Acesso 27 jan 2018.

BARBOSA, J. L. M. Geometria Hiperbólica. 5a impressão. Rio de Janeiro: IMPA, 2009. 
BORTOLOSSI, H. J. Latitude e Longitude: Representando Pontos na Superfície da Terra. 2006. Disponível em http://www.professores.uff.br/hjbortol/arquivo /2006.1/applets/earth br.html. Acesso em 28 ago 2014.

BRASIL. Ministério da Educação. Secretaria de Educação Fundamental. Parâmetros Curriculares Nacionais: Matemática. Brasília: MEC, 1997. 1ํㅡ e ํㅜciclos.

BRASIL. Ministério da Educação. Secretaria de Educação Fundamental. Parâmetros Curriculares Nacionais: Matemática. Brasília: MEC, 1998.

BRASIL. Ministério da Educação. Secretaria de Educação Média e Tecnológica. Parâmetros Curriculares Nacionais (Ensino Médio): Matemática. Brasília: MEC, 1999.

BRITO, A. J. Geometrias não-euclidianas: um estudo histórico-pedagógico. 1995. $187 f$. Dissertação (Mestrado em Matemática) - Faculdade de Educação, Universidade Estadual de Campinas, Campinas, 1995.

COUTINHO, L. Convite às Geometrias Não-Euclidianas. 2 ed. Rio de Janeiro: Interciência, 2001.

D' AMBROSIO, Ubiratan. Educação Matemática: Da teoria à prática. Campinas, SP: Papirus, 1996.

DANTE. L. R. Matemática. Volume único. São Paulo: Ática, 2008.

EUCLIDES. Os Elementos. Tradução e introdução de: Irineu Bicudo. São Paulo: Ed. UNESP, 2009.

FAINGUELERNT, E. K. Educação Matemática: Representação e Construção em Geometria. Porto Alegre: Artes Medicas Sul, 1999.

FAINGUELERNT, E. K.; NUNES, K. R. A. Matemática: práticas pedagógicas para o ensino médio. Porto Alegre: Penso, 2012.

FRANÇA, L. Imagens e números: interseções entre as histórias da arte e da matemática. Aracaju: UFS - Fundação Oviedo Teixeira, 2008.

FONTE, C. Superfícies e sólidos geométricos. Geometria Descritiva. Faculdade de Ciências e Tecnologia da Universidade de Coimbra. Portugal, 2006/2007. Disponível em: http://www.mat.uc.pt/ cfonte/docencia/Geometria\%20_Descritiva/7_Superf\%C3\%ADcies $\% 20$ e\%20solidos.pdf . Acesso em 26 jan 2018.

GARBI, G. A rainha das ciências: um passeio histórico pelo maravilhoso mundo da matemática. São Paulo: Editora Livraria da Física, 2006.

GRAVINA, M. A. Geometria dinâmica: uma nova abordagem para a aprendizagem da Geometria. In: Simpósio Brasileiro de Informática na Educação, Belo Horizonte, 1996. Anais. Belo Horizonte, 1996. Disponível em: http://www.ufrgs.br/espmat/disciplinas/geotri/pdf/mariaalice geometria/dinamica 
1996-vii sbie.pdf. Acesso em 27 jan. 2018.

KALLEF, A. M. M. R; ROIBAINA, D. T; NASCIMENTO, R. S. Geometrias Não Euclidianas do caminhar nas cidades ao funcionamento do GPS. In. Encontro Nacional de Educação Matemática, IX, 2009, Belo Horizonte. Disponível em http://www.sbem.com.br/files/ix enem/html/minicursos.html. Acessoem 12 jan 2018.

KATZ, V. J. A. A history of mathematics: an introduction. 2 ed.Addisson: Wesley, 1998.

LIMA, E. L. Meu professor de Matemática. IMPA, Rio de Janeiro: Gráfica Vagner Ltda, 2001.

O’SHEA, D. A solução de Poincaré. São Paulo: Record, 2009.

PONTE, J. P.; BROCARDO, J; OLIVEIRA, H. Investigações matemáticas na sala de aula. Belo Horizonte: Autêntica, 2003.

SOUZA, Pedro M. Fialho. Superfície Esférica I. Universidade de Lisboa. Portugal, 1997. Disponível em http://home.fa.utl.pt/ Immateus/materiais_apoio/superficies_

esférica.pdf. Acesso em 02 out 2014.

TOMAZ, M. L.; FRANCO, V. S.Geometria Não Euclidiana/ Geometria Esférica. Programa de Desenvolvimento Educacional do Estado do Paraná, PDE 2007/2008. Disponível em: http://www.gestaoescolar.diaadia.pr.gov.br/arquivos/File/producoes _pde/md_mara_lucia_thomaz.pdf. Acesso em 19 jan 2018.

VELOSO, E. Geometria: temas actuais - material para professores. Lisboa: Instituto de Inovação Edicacional, 1928

ZANELLA, I. A. Geometria Esférica: uma proposta de atividades com aplicações. 2011. Dissertação (Mestrado Profissional em Matemática em Rede Nacional), Universidade Estadual de Londrina. Londrina, 2011. Disponível em: http://bit.profmatsbm.org.br/xmlui/bitstream/handle/123456789/230/2011 00069 IDELMA $\underline{\mathrm{R}}$ ANDRE ZANELLA.pdf? sequence=1. Acesso em 25 jan 2018. 